\title{
The Experience of Illness in Early Twentieth-century Rural Shanxi
}

\author{
Henrietta Harrison \\ University of Leeds
}

What do people do when they are sick? ${ }^{1}$ How do they make sense of what is happening to them? What medicines do they take and who recommends them? What kind of professional help do they seek? How do all these things change over time? Over the last twenty years many scholars of European and American history have looked at these questions and, in doing so, have transformed our understanding of medical history. ${ }^{2}$ They have done so in large part by focussing on self-treatment and on informal, nonprofessional, non-specialist healthcare. As early as 1980 Arthur Kleinman, in a pioneering anthropological study, argued for the importance of this sector to our understanding of Chinese medical culture. ${ }^{3}$ However, his work was aimed at understanding the contemporary situation and there have as yet been few historical studies of patients and their choices. Chang Che-chia has provided us with a brilliant glimpse of the Qing imperial family’s choices of treatment in the late nineteenth century, but the imperial family are by definition a rather unusual group: few other patients could consider executing their doctors. ${ }^{4}$ We also have several recent studies which have grown out of the flourishing field of social and literary history of the late Ming and early Qing. ${ }^{5}$ This paper, which is based on the diary of a Shanxi 山西 villager, will I hope contribute to our understanding by describing the treatment choices of someone who lived in a rural area and was considerably lower down the social scale than the subjects of existing 
studies. Secondly, the paper focuses on a key moment of social and political transition, the early twentieth century, to try and get a sense of how lay attitudes towards medicine were changing at that time and especially how the new Western bio-medicine affected people's choices of treatment. Bridie Andrews, in a recent study of the adoption of germ theory in early twentieth century China, has argued that we need to consider not just the export of Western medical ideas to China but also how and why they were appropriated by the Chinese. ${ }^{6}$ This is undoubtedly true and not only of the elite members of the medical profession whose written works she examines, but also of the lay public in areas outside the heavily Western-influenced treaty ports. Thus the second part of this paper looks to see what kind of bio-medical ideas and practices were available to a Shanxi villager and how these were incorporated into the existing medical culture.

The paper is based on the writings of Liu Dapeng 劉大鵬 (1857-1942). Liu was born in 1857 in Chiqiao 赤橋 village not far from Taiyuan 太原 city the capital of Shanxi. His father had begun life poor, but as the result of a ferocious work ethic had prospered and bought a furniture store in Taigu 太谷 county a day’s journey from the family home. Liu Dapeng was his only surviving son and when the boy proved good at school he became the subject for his father's driving ambition. He was educated in the village school and then in the provincial capital and succeeded in passing the prestigious juren 舉人 degree, which made the holder eligible to travel to Beijing and take the national examinations for government office. He attempted these exams three times but failed. Meanwhile he worked as a tutor for a wealthy merchant family in a village in Taigu county. Around 1908 he lost his job as the result of the modernisation of the education system and returned to Chiqiao where he passed the rest of his days. At first 
his degree gave him status in the local community and he was able to capitalise on that as a manager of a local coal mine. In later years he farmed the family's small plot of land, working all day in the fields alongside his young grandchildren and a single hired hand. When he died in 1942, during the Japanese occupation, his family was virtually destitute and relied on gifts of food from kindly relatives. In 1948 his remaining sons and grandsons were classified as poor peasants, except for the youngest who was just wealthy enough to count as a middle peasant. ${ }^{7}$

Liu Dapeng kept a diary for fifty years from 1892 until the day before his death in 1942. ${ }^{8}$ He wrote in it daily, sometimes several times a day, recording his activities but also moral and ethical meditations, poems, local events and any interesting news he heard or read. The problems with using diaries as a historical source are well known and scarcely need rehearsing here. Very few individuals can ever be said to be representative of their time, region or social class, and diary writers are unusual simply by dint of the fact that they felt the urge to record their lives. Diaries are valuable historical sources not because their writers are representative but because they give us access to the kinds of information that other sources seldom do, and Liu Dapeng's is no exception. His diary gives us a rare insight into the medical treatments available in a Shanxi village, who provided them, and how they were understood. Like many diary writers Liu records the details of his own ailments as well as some information about the illnesses of other family members. In 1914, for example, he describes five different occasions on which he was ill: in the late winter he had a hard red swelling on his buttocks which went away without medication; then in the early spring he had a fever, for which he rested in bed and took laxatives; later he developed a sore throat which he ascribed to fire in the stomach; 
in the summer he got a bad attack of fever lasting several days for which he took ginger soup, laxative pills, opium (to counteract the laxatives), and then alcohol mixed with brown sugar; he ended the year with a brief attack of diarrhoea in the early autumn. ${ }^{9}$ Some of these episodes are passed over in a few words, but others are described in considerable detail as he ponders over the cause of the illness, chooses what medicine to take, describes the effects of the medicine and receives advice from his family, friends and neighbours. Occasionally his illnesses were serious enough to warrant the expense of professional help. Used alongside other sources from the area, the diary enables us to build up a picture not only of Liu Dapeng's experience of illness but also of the medical culture of the village.

\section{Disease and ill-health in the village}

The pattern of disease in Chiqiao was similar to that in many other densely populated pre-modern societies with a mixture of violent epidemics and painful chronic conditions. Infectious diseases were the major cause of death. In 1919 a survey in Liu Dapeng's home county found that the commonest cause of death was old age, recorded for $29 \%$ of men and $21 \%$ of women. Apart from this most deaths were due to measles and scarlet fever (11\%), diphtheria (7\%), typhoid (7\%) and smallpox (4\%). The report also listed a smaller number of deaths from accidents, suicide, cholera, consumption, choking, childbirth and a weak constitution. ${ }^{10}$ Ten years later the situation had changed little. A survey of Jinci 晉祠 town, just half a mile from Chiqiao, and four nearby villages found that the most common causes of death were consumption and measles followed by typhoid, diphtheria and cholera. ${ }^{11}$ The particular pattern recorded in any 
survey depended on which epidemics had happened to strike the area recently. Cholera was particularly terrifying since it was not endemic and therefore killed large numbers of adults as well as children. ${ }^{12}$ But the county also saw violent epidemics of diphtheria, typhoid and smallpox: in an outbreak of diphtheria in 191350 children died in the village of Jinsheng 金勝 which had only 154 households. A traveller's report written a few years later suggests just why diphtheria in Jinsheng was so deadly: the village lay on the main north-south road so the villagers had built their toilets out into the road in front of their houses to attract the passing custom. When the weather was dry the noxious vapours rose up from them and when it was wet the contents overflowed. In any case the villagers would often casually put their food down on the low walls of the toilet as they wandered into the street to chat and eat. ${ }^{13}$ But it was not only in Jinsheng that epidemics spread easily. The county government, reporting on why it had failed to enforce a provincial hygiene initiative in the 1930s, explained that it was very difficult to change the custom of using the area in front of the house to dry nightsoil before using it for fertiliser. ${ }^{14}$ An acquaintance of Liu Dapeng's, who lived in nearby Xugou 徐溝 county, pointed out that the drinking water in wells was contaminated by piles of rubbish, coal heaps, and pits for fermenting nightsoil, which stood nearby with nothing to prevent seepage. ${ }^{15}$ Problems with hygiene appalled the modern-educated elite of the province who recorded these circumstances, but the violence and frequency of epidemics was also due to poverty and hunger. A missionary in the south of Shanxi noted that there were epidemics every spring because of the poor quality of the food used by the poor when they ran out of wheat at the end of the winter. ${ }^{16}$ Across the province drought and famine regularly led to epidemics. In 1901, when drought was exacerbated by the extraction of 
the Boxer indemnity, Liu Dapeng wrote in anger that there was an epidemic in the county and because families had no spare grain many people had died. ${ }^{17}$

As well as infectious diseases people also suffered from a great variety of permanent disabilities and painful chronic complaints. A survey of a village in Taigu county in the mid 1930s found that 33 people (4\% of adults) had serious physical disabilities, that is to say they were blind, deaf, lame, hump-backed, mentally deficient, partially paralysed or suffered from nervous illnesses. ${ }^{18}$ Sometimes disabilities were linked to infectious diseases: much blindness was caused by smallpox. ${ }^{19}$ People also suffered from less serious, but nevertheless, painful complaints. Skin diseases giving rise to painful sores and ulcers were particularly common. ${ }^{20}$ In 1925 Liu Dapeng had a sore at the back of his neck that lasted for four months. It was swollen and painful. To treat it his son used a small bowl heated to produce a vacuum and then placed over the sore. This resulted in a stream of blood and pus flowing constantly from the sore for days on end. People lived with such illnesses. Missionaries working in the village where Liu's father kept a shop recorded large numbers of patients with tumours, sore, ulcers and abscesses. Many of these only turned to missionary doctors in despair after suffering for some time..$^{21}$

Illness of any sort could be a financial disaster. In 1926 two of Liu's sons became ill with a violent fever. Soon Liu's wife, son's wife and four grandchildren were also seriously ill. In the end all the adults recovered but two of the children died. The outbreak lasted nearly two months and during that time a doctor visited regularly and the sick all took medicine. ${ }^{22}$ Liu was devastated at his grandchildren's' deaths, but he also noted in his diary that the family's medical expenses had been huge and that as a result 
his expenditure had been greater than his income that year. ${ }^{23}$ Some years earlier, when his previous wife was dying he spent between 20 and 30 taels on doctors fees and

medicine. This was approximately a quarter of his annual income from teaching. ${ }^{24}$ Such large expenses caused the family to lose money, but Liu was well paid when he worked as a teacher and they could afford it. Others were not so lucky. Missionaries told the story of a woman who had lost her job as a servant when she became blind with cataracts and had twice attempted suicide, and of a man who turned up at their small hospital with a son with a broken leg saying that he had sold his wife so he could leave his work and care for his son till he got better. ${ }^{25}$ Illness was pervasive, violent, painful and the expenses involved could easily tip people from poverty into destitution and despair. So how did people make sense of it and what did they do in response?

\section{Interpreting illness}

Liu Dapeng was strongly committed to the Confucianism he had been educated in. Like many religious believers in early modern Europe, and indeed at many other times and places, he interpreted sickness in providential terms. In practice this meant that he understood most of the illnesses that afflicted himself or his family as a form of divine punishment or warning. Thus in 1925 when he was ill with a sore at the back of his neck he wrote:

Last night I went to bed at the second drum but tossed and turned and could not sleep because the sore on my head was painful. This illness began many days ago and it is ten days since the sore became serious. The retribution is great because my 
sin is deep and ought to be punished. So having a sore that hurts all the time day and night is no different from a penalty for crime. Punishment is not unreasonable but fits the crime and in the same way sickness is not unreasonable but is a form of retribution. How could the present sore on my head have arisen for no purpose? Heaven is warning me. ${ }^{26}$

It is only occasionally, however, that he actually records what he thinks an illness is punishment is for. In 1908 he had diarrhoea and attributed it to his failure to carry out the correct mourning ritual after his father's death the previous year. This was a crime against the cardinal virtue of filial piety and Liu cried noisily in the small hours of the morning when he thought about how angry Heaven must be with him. ${ }^{27}$ On another occasion, when he heard that the great revolutionary Sun Yatsen 孫文 (1866-1925) was ill and near to death, Liu commented that the Western-style medical operation that Sun had undergone made his death the equivalent of the judicial system's terrible penalty of death by slow slicing. ${ }^{28}$ In this case it is clear that it is Sun's treachery and rebellion that are being punished. However, usually Liu makes no such specific connection and merely interprets his illnesses as the inevitable result of a generalised sin.

Liu's providential explanations imply that illness is a disruption of the physical order of the body caused by a disruption of the moral order of the universe. Since as a committed Confucian he believed that the moral order of the universe was based on the five basic human relationships (between sovereign and minister, father and son, elder and younger brothers, husband and wife, and friends), illness was inevitably a social matter. This applied to illnesses affecting individuals and also to those affecting the community 
as a whole. Liu Dapeng wrote, and presumably talked, about his own and others illnesses in ways that were intended to enforce this Confucian vision of the moral order. Thus he wrote that the sudden death of the wife of his neighbour the shoe mender Cao Dinghai 曹 丁亥 was a punishment for the couple's ill-treatment of Cao Dinghai's mother. He quotes the Classic of Filial Piety 孝經 to the effect that lack of filial piety is the worst possible crime and explains that Cao Dinghai's wife was executed for it. ${ }^{29}$ Occasionally Liu also used the cures of his illnesses to illustrate the same point, as when he developed a painful swelling on his buttocks shortly before having to ride a considerable distance by mule. Despite the riding the pain stopped and he told his family that this was a reward for his virtuous thoughts. ${ }^{30}$ In such remarks Liu used the idea of illness as a punishment for sin to try and alter the behaviour of those around him and inculcate his own idea of the moral order. However, the idea of illness as a punishment also worked to reinforce social ties in other more obvious ways. For in many cases the person who became ill was not the person who had transgressed the moral order. Thus when Liu describes the death of Cao Dinghai's wife the language he uses makes it appear that the fault lay primarily with Cao, and yet it is Cao’s wife who becomes ill. Similarly when Liu's son and grandchildren became ill in 1926 he attributed their illnesses to his own lack of virtue. ${ }^{31}$ Thus the moral interdependence of the family is reinforced by the divine sanction of illness.

The family was not the only community whose interdependence was emphasized by illness. When an epidemic followed the Boxer Uprising Liu noted that the high death rate was due to the shortage of food, but also attributed the deaths to the "wickedness of customs and human feelings". ${ }^{32}$ I doubt Liu’s friends and neighbours always agreed with 
his interpretations of their individual illnesses, but the idea that epidemics were a divine punishment of the whole community for immoral behaviour was certainly widespread. Chiqiao villagers responded to such ideas by organising sacrifices, which Liu attended, to the Plague God. The sacrifices were performed by a Buddhist monk and involved the recitation of scriptures and prayers asking the Plague God to have mercy. Afterwards people walked through the streets put up lanterns to drive out the Plague God and beg for peace for the village. ${ }^{33}$ The monk's prayers were for the community as a whole and as the villagers processed through the streets they were binding the community together. Here again illness reinforced the idea of social interdependence and the response worked to bring the community together.

Providential explanations were no bar to seeking a cure through physical means. Indeed when his illnesses lasted a long time, Liu mixed laments for his sinfulness with his record of the search for different treatments. Thus in 1925 when he had the sore on his head he initially ascribed it to fire in the stomach which had caused a blockage, and took a strong laxative in response. A couple of days later he was still taking laxatives but also regretting that his wicked deeds had angered Heaven. Later his sons tried smearing the sore with egg whites and putting a heated bowl on it to create a vacuum and draw out the pus. He interspersed his accounts of these treatments with contrition for his wickedness which has caused the affliction. When his family suggested getting a doctor he refused on the grounds that the sore was a punishment and in any case doctors these days were no use. In the end one Li Liangshan 李良善, who may or may not have been a professional doctor, came several times to apply a wheaten poultice while Liu continued to take laxatives and also took a prescription given by another friend who was a teacher. 
When the sore eventually healed he attributed this to the fact that his sin had now been wiped out. ${ }^{34}$

\section{Treating illness}

\section{$\underline{\text { Self-medication }}$}

The way in which Liu Dapeng interpreted his illnesses shaped his response to them and especially the kind of medication he expected to use. The explanation of illness as a punishment imposed by Heaven was reflected at the physical level in the idea that most illnesses come from outside the body and need to be expelled. This understanding is also suggested by the treatments Liu used. As the account of several of his illnesses has already suggested, his first response to almost any problem was to purge himself. The particular laxative drugs he used changed through time. In the 1900s he used a panacea called Ten-Thousand Gold Pills (Wanjindan 萬金丹); in the 1920s he used another laxative called River Army (Chuanjun 川軍). In his old age he also took a type of rhubarb though his family used to try to prevent him. ${ }^{35}$ They objected that it was too strong, but this objection was probably also driven by the fact that by the 1930s fashions in medicines had shifted towards milder herbs and Liu's frequent use of powerful purges was old fashioned. Liu Wenbing 劉文炳 (1876-1954), an acquaintance of Liu Dapeng's, looked up the accounts of medicine shops in his home county and found that between 1868 and 1929 the quantity of herbs sold had risen from 558 catties to more than 4,000 catties and the quantity of rhubarb-based drugs used for purges had fallen from 3,233

catties to just 150 catties, with the biggest drop occurring between 1891 and $1900 .{ }^{36}$ In the 1880s when Liu was young his use of laxatives was evidently commonplace. A 
missionary doctor working in Taiyuan city at that time noticed that many patients explained their illnesses by saying that food had got stuck in the chest and could not go down, or that there was a large solid lump in the stomach which nothing could dissolve. He recorded these cases as dyspepsia and presumably the treatment fitted with this explanation. ${ }^{37}$ The other medicines that Liu regularly took were forms of opium (either the drug itself or a medical preparation called Chenanxiang 車楠香). Opium induces constipation and was used to counteract the effects of the laxatives. ${ }^{38}$

The same interpretation of illness as something within the body that needs to be expelled is suggested by his use of the term “poison”. When blisters on his neck began to flow with pus Liu explained, "I think that it is because the wind I caught has now turned into poison.”39 For persistent and painful sores he used a combination of poultices and vacuum bowls, both of which were designed to draw the poison out of the body. The poultices were usually made from readily available ingredients: fried spring onions, willow leaves, and egg whites. ${ }^{40}$ An educated friend explained that causing the sore to open would make an exit and the poultice would then draw the poison out. ${ }^{41}$ The vacuum bowl, which was often used at the same time, was intended to have the same effect. The bowl was a small ceramic pot with a narrow mouth. A strip of paper or a scrap of cotton was set alight and put into the bowl which was then placed over the sore. The flame created a vacuum and fixed the bowl to the body. After a few minutes the bowl was pulled off. This usually had the effect of drawing liquid out of a sore. Liu

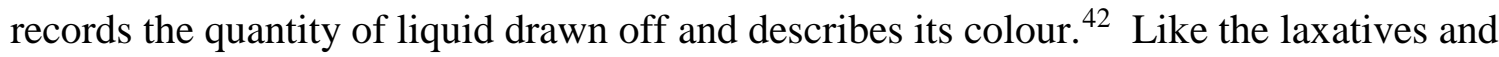
poultices the vacuum bowl was intended to expel the poison from the body. Indeed when he became ill with a sore on his neck in 1925 Liu used laxative River Army soup, egg 
white poultices and a vacuum bowl in a series of attempts to draw the poison out. The image of illness as caused by an agent, such as "wind", entering the body and then being expelled is, of course, part of the basic outlook of China's classical textual tradition of medicine, but Liu's interpretation of it is much simpler than that of the medical texts. Indeed there is no indication that he had read any medical texts, instead his responses would seem to reflect a more popular understanding of illness and medication.

This is also suggested by the fact although he occasionally records a prescription most of the medicines he used were bought ready-prepared. In addition to the laxatives and opium-based drugs he lists Nine Dismissal Medicine (jiusanyao 九散藥), Nine Immortals Pills (jiuxiandan 九仙丹), Six Deities Pills (liushenwan 六神丸) and many more. ${ }^{43}$ Pharmaceuticals of all kinds were highly commercialised, with advertising both in the newspapers and on handbills for a large variety of treatments. On occasion Liu, too short of money to afford proper paper, wrote his diary on the backs of handbills issued by local medicine shops. Because of the way the pages of the diary were glued, folded and sewn together these are not usually visible, but occasionally the flimsy paper has perished at the fold and we catch tantalising glimpses of these simple wood-block prints. There is an advertisement for the Dehe Medicine Shop in Jinci, the nearest small town. It promises that the store buys directly from Sichuan and Guangdong, the major producers of medicines, and lists some of the pills, lozenges and liquid preparations which it sells. ${ }^{44}$ Another handbill is for a specific medicine: Golden Pills for Rescuing the Generations (jishi jindan 濟世金丹). The handbill is illustrated by a picture of an old man and two children and the name is a euphemism for the function: this is an antiimpotence pill. The handbill states that it is made by the Liangji Pharmacy in Chongqing 
and that it is "one of the best prescriptions in China or abroad". The local dealer has stamped his store's name on the handbill and a promise to sell the pills at half the advertised price. ${ }^{45}$ When Liu Dapeng bought medicines for himself or his family, he was taking part in a popular medical culture that mixed personal experience (he used to sun his legs once a year because it had helped once), local products (eggs, willow leaves, spring onions) and national commerce. ${ }^{46}$ This culture which he shared with his family and neighbours shaped not only his response to and interpretation of his illnesses but also the means available to treat them.

\section{Family, friends and neighbours}

Liu Dapeng's response to illness was shaped by the community, but it also helped to shape that community. For if illness was a divine punishment then a cure was not merely a matter of finding a drug to expel the poison, but also a process of rebuilding the proper social and moral order. Family, neighbours and friends provided widening circles of community whose actions in relation to the sick person could thus reaffirm the proper order of things.

The sick person's primary relationships were with his or her family and family members were the first to provide care once the illness had gone beyond self-medication. Liu's parents, wives (he was twice widowed) and later his sons expressed their concern and affection for him by suggesting and helping with new treatments. Caring for the sick was a moment when family members could act out the emotions appropriate to their relationships. Thus when Liu was ill with a sore on the back of his neck it was his sons who first prepared egg whites to put on the sore and then borrowed a vacuum bowl to try 
and draw the poison out. One of them then applied the bowl to the sore twice a day. ${ }^{47}$ Similarly when Liu was sick with diarrhoea a year later and his eldest son was at home, his wife found a pill based on aconite for him to take and his son boiled up a basin of another medicine for him to take. ${ }^{48}$ When Chang Zanchun 常贊春 (1872-1941), a wealthy acquaintance of Liu's, wrote a biography of his wife, Qiao Yiren 喬宜人, he narrated her fulfilment of the Confucian roles of daughter, wife and daughter-in-law by telling of the commitment with which she cared for her mother, him and his mother when they were ill. She bathed her mother, brought medicine and dressed her sores. When her mother-in-law was ill she took on the heavy labour of lifting and washing her. ${ }^{49}$ Chang Zanchun's family was both large and very wealthy; it is obvious from his description that there was no necessity for his wife to perform such exhausting labour. As in the case of Liu Dapeng's sons and wife, Qiao Yiren's actions were an expression of affection and duty. The ultimate expression of such care was to feed a sick parent one's own flesh. Liu could have read in the local newspapers of just this happening in 1924, when a widow in northern Shanxi cut a piece of flesh from her leg to feed sick father-in-law. ${ }^{50}$

The business of curing the sick was also a means through which the hierarchy of power within the family was acted out through the expression of affection. When Liu's parents were still alive it was they who found medicines for him when he was ill and ordered him to take them. ${ }^{51}$ Similarly, when he became ill while he was working as a tutor, his employer not only provided expensive medicines but also wrote prescriptions for him. ${ }^{52}$ Actions taken to care for and cure the sick demonstrated the personal concern that should properly underlie particular relationships. These were centred around the family, but spread beyond it to all those who lived in the household. Liu's employer 
provided medicine and prescriptions for him and when Liu himself became an employer and his long-term hired labourer Old Fourth Wang became ill Liu too arranged for a doctor and medicines. ${ }^{53}$ Thus people responded to illness in ways that reinforced the moral order of the family and household.

When illnesses became too serious to be cared for within the family people turned to their neighbours. Several people in Chiqiao village had particular types of medical expertise. Indeed Liu himself was one of these. Every year in the summer he would steep snake, lizard, scorpion, centipede and toad in alcohol. He kept the jar through the year and would hand out the liquor to villagers who asked for it when they were sick. He also handed out Ten Thousand Gold pills, his favourite laxatives, to his neighbours. And he was occasionally called on, usually in the middle of the night, in cases of attempted suicide by opium poisoning for which he had a medicine, which appears to have been some kind of emetic, kept in a Western-style blue glass bottle with a label. ${ }^{54}$ Liu occasionally records the outcome of these cases, but his own role was limited to handing out the medicine and giving instructions on how to use it.

Other villagers possessed certain skills or knowledge that involved actually visiting the sick person at home. Most of the cures these neighbours applied were practical, inexpensive and little different from those used by family members, but there was clearly also an element of specialisation. Thus, when Liu's younger son became violently ill with a fever in the middle of the night another son hurried to fetch a neighbour who knew how to perform acupuncture which would keep the illness under control until the morning. It was not until the next day that a doctor could be fetched to provide a prescription. ${ }^{55}$ Acupuncture was regarded as a simple technique that could be 
used by lay people. The neighbour clearly had a level expertise (that was why he was fetched), but he was not educated and it was Liu's family who decided at which points the needles should be inserted. The terminology used refers to the classical system of acupuncture, but piercing with needles was often seen as a way of letting the poison out of the body. Missionaries describe local doctors' custom of piercing a painful part with needles "to let the evil spirit escape." ${ }^{56}$ Liu had needles applied to his neck when it was painful and in another case one of his sons had needles applied to the swollen pustules in his throat. ${ }^{57}$ This use of acupuncture to lance sores and blisters is not compatible with the classical explanations. Instead, as with self-medication and the help provided by family members, we see people providing treatment which is based on the simple assumption that illness is something poisonous within the body which must be expelled.

Several of the villagers who were called in for their medical expertise were women. In 1901 Liu's parents asked an old woman to come and try to cure the sore on his neck. She applied a poultice of ground almond shells, earth, spit and flour. The next day she returned to apply moxibustion to the sore which came up in blisters and oozed pus. Finally she used a poultice of alum, a mineral that was mined locally, to press onto the sore. ${ }^{58}$ In this case the treatment was ineffective, but Liu makes no criticism of her. On other occasions village women were called in to deal with gynaecological complaints. When Liu's wife had stomach pains after giving birth she took a prescription provided by a certain Woman Chuan 傳氏. Later when one of Liu’s daughters-in-law developed an ulcer after giving birth the wife of neighbour Ren Wei 任偉 was invited to heal it by drawing out the blood and pus. ${ }^{59}$ Women like these did not provide an interpretation of the illness, or at least one that Liu thought worth recording. Instead he interprets their 
actions himself, explaining for example that Ren Wei's wife is drawing out the poisons brought about by the infection. Nevertheless it is clear that the actions they took fitted easily into the framework of his thought.

Neighbours who provided medical help were recompensed. When one of Liu's sons was ill in 1927 a Chiqiao man called Guo Jinhai 郭金海 examined him. The family gave Guo a pound of arrowroot and 300 sheets of paper in payment. (Paper was a form of currency since paper-making was the village’s main industry.) However, the family also continued to conduct elaborate social relations with Guo’s family, as when not long afterwards Liu's grandson helped at Guo's son's wedding. ${ }^{60}$ Indeed in many cases the recompense was in itself a form of social interaction. When Liu's young wife gave birth to a daughter in 1925 she became seriously ill, but the neighbours rallied round and, with the help of Woman Chuan's prescription, she survived. Forty days later Liu gave a dinner for two tables of guests, one of men and one of women, to thank them for their help. Neighbours who provided medical help were recompensed, but not necessarily in cash. Liu himself would undoubtedly not have accepted cash payment for the medicines he handed out. ${ }^{61}$ The importance of medical experts who operated outside the formal cannon is just now beginning to be recognised, but by referring to these people as lay healers there has been a tendency to imply that they were more professional than at least Liu Dapeng’s records suggest. ${ }^{62}$ Medical care was given as part of the elaborate network of social relations. And like help given within the family, help between neighbours was part of the process through which the moral order of the community was formed and strengthened. As all this implies the boundary between assistance that grew out of personal relationships and proper human emotions and the employment of a professional 
was vague. Help in curing a sick person was conceived of in terms of generosity and concern that grew naturally out of human relationships. This worked well when medical advice could be sought from friends and neighbours, since in both cases one had an ongoing social relationship.

Liu Dapeng himself was highly educated and had a circle of educated friends to draw on for medical advice as well as his neighbours. The elite textual tradition of medicine was open to anyone who was sufficiently literate and could spend time studying published medical texts, and several of Liu's friends had become medical experts. Much of the advice phrased in terms of the classical medical tradition that Liu received came from these friends. So, for example, Qin Ronghang 秦蓉航 was a degree holder who had acted as Liu's son's guarantor for the exams in the 1890s. He and Liu then had a further connection since both had been appointed inspectors of the county academy. Many years later when Liu's daughter-in-law was ill, he happened to meet Qin Ronghang in the road and invited him in to examine her. Qin Ronghang did so and wrote a prescription for her to take. ${ }^{63}$ The vocabulary of examining the patient and writing a prescription makes it clear that Qin Ronghang was operating within the elite textual tradition of medicine. Thus the encounter was professionalised to the extent that it was dictated by Qin's studies of the texts, but was framed within a personal friendship. However, the clearest example of the combination of the elite medical tradition and personal friendship is the case of one of Liu’s closest friends Hu Ying 胡瀛 (1866-1935). Hu Ying was nine years younger than Liu but studied in the same academies and was already a close friend in the 1890s. He subsequently became involved in the modern education system and became head of the provincial college for primary teachers. His family was wealthy and Hu built up a 
large personal library and spent his spare time in his later years studying Buddhism and medical texts. When two of Liu's daughters-in-law were ill Hu came repeatedly to examine and prescribe for them. He explained the cause of the illness as "catching the wind" and prescribed a medicine suitable for pregnant women who had caught wind or cold. He regularly changed his prescriptions to follow the progress of the disease. On one occasion Liu went to fetch him in the rain. Hu came, examined his patient, changed the prescription and went home again in the rain without even staying for a meal. Liu remarked that his behaviour "could be said to be the strongest example of feeling between friends”. ${ }^{64}$ Medical help from friends, like help from neighbours or within the family, involved the highly visible performance of proper human relationships and as such it responded to the moral as well as the physical causes of illness.

\section{$\underline{\text { Professional doctors }}$}

However, different people had different areas of medical expertise and it was frequently unavoidable to invite a doctor with whom the family had no other social links. Such a doctor was likely to be an expert in the elite tradition of textual medicine and to be making a living largely, if not entirely, from the practice of medicine.

Liu tells us little of the doctors who attended the family in this way, though on one occasion he praises a friend who has been earning a living as a doctor for several years but has realised how easy it is to kill people through the unskilled practice of medicine and has therefore returned to work on his farm. ${ }^{65}$ Liu's account implies that the man had some education and a small amount of land and that these provided his only alternatives to practising as a doctor. An account of a doctor called Xue 學 who became 
well known in a neighbouring county gives an indication of the kind of background of such men which fits well with such snatches of information as Liu provides. Xue began his life working in a shop but became ill and had to return home. There he studied medicine to cure himself and worked on his farm. He was forty before he began to practice as a doctor. He developed a reputation for curing fevers and women's complaints both of which were common in the villages where he worked. His practice did not make him wealthy and unless his patient's family sent a cart to fetch him he walked to the villages where he worked ${ }^{66}$ Official medical histories record several doctors who had similar backgrounds as well as others who came from medical families or were apprenticed to pharmacies ${ }^{67}$ However, the life stories of famous doctors may well distort a pattern where the life-history of Xue which combined self-study, relative poverty and farming was in fact quite common.

Any professional doctor was dependent on the money he earned from his practice to make a living. This was inherently problematic for Liu with his commitment to the Confucian moral order, which made him deeply unhappy with the idea of profit as a motive for doctors. His attitudes grew out of a long tradition of antipathy to doctors, which is expressed in the classical texts where doctors are regularly suspected either of acting solely for their own profit or of being incompetent. ${ }^{68}$ In Liu’s case the arrival of a doctor in the family was almost always an occasion for him to voice his disapproval of doctors who, unlike the sage doctors of the past who had written the medical texts, were motivated by profit rather than compassion. ${ }^{69}$ His distrust of doctors who interacted with him and his family on a purely professional basis is illustrated by remarks made in the 1890s: 
Most of those who practise medicine are wicked and do not think of saving lives, the only thing they care about is money. When they see patients they boast about their skills, raise their prices, and only attend if they are offered a lot of money. If they are offered too little they stay away, even if the patient is in desperate need, and do not even ask after him. It is so bad that in a crisis when a man may not survive the day they sigh and say that there is no cure, but if you give them a bit more money they assure you that all will be well. Nine out of ten doctors are like this. Is this not wickedness! ${ }^{70}$

Worse still doctors exploited the families of the sick. One of Liu's standard complaints is that a doctor will go to see a patient when the whole family is desperate with anxiety and then demand a meal from them. Indeed Liu records this happening to his own family in the 1920s when several family members were suffering from a condition involving a serious fever and violent diarrhoea. They invited a doctor and he came in the afternoon but still expected to be fed. Lunch was already over and now more food had to be prepared. Liu was evidently extremely annoyed and commented,

The fact that he was determined to have a meal when he was seeing the patient demonstrates that he lacks proper human feelings. To come late and then give the family a whole lot of trouble was using his skills to behave in an arrogant and really objectionable way. ${ }^{71}$ 
A few days later Liu was still complaining that every time the doctor came the family had to provide him with lunch. ${ }^{72}$ Liu is more critical of the moral character of doctors than any other group of people he regularly encountered with the possible exception of taxcollectors. It is possible, but surely unlikely, that doctors were more venal and immoral than mine-owners, military officials or the bankers who led the local business community. Instead it seems more plausible that Liu found the activity of the professional doctor inherently distasteful. This is indicated by the story he tells of a local doctor who was punished for the greed with which he had hoarded money by his death which was soon followed by the death of his only son leaving his wife to sell the family property and remarry. In Liu’s view this was an appropriate punishment or a man who had earned his money from the families of the sick. ${ }^{73}$

The implication of this emphasis on the immoral behaviour of doctors is that they cannot really have studied. For Liu, a true study of the classical texts would lead inevitably to proper moral behaviour, like that of his friend Hu Ying who came to write a prescription for Liu's daughter-in-law and left immediately to walk home even though it was raining. Consequently Liu thought that the majority of doctors had not truly studied but were ignorant charlatans who had never really understood the classical texts and were therefore unable to make a living from any other walk of life. ${ }^{74}$ Indeed he recorded stories of the terrible effects of the incorrect medical treatment prescribed by doctors, as when a man from the county town caught a cold wind on a short journey. The doctor gave him a tonic so that the wind had no way out of the body and congealed in his chest. He died shortly afterwards. ${ }^{75}$ The implication of Liu's story is that what the man really needed was a purge of some sort. It might be possible to explain this story by suggesting 
that local doctors disagreed with Liu Dapeng's interpretations of illness with their emphasis on driving out poisons, but Liu himself simply puts the events down to medical ignorance and other people agreed. A Taiyuan county government document written in the 1930s explains that intelligent and knowledgeable men do not become doctors and those who do are usually the kind of people who hang around the marketplace. They do not understand how to take a pulse or ask about the symptoms so recovery is a matter of luck and one may as easily be killed by the doctor as cured. ${ }^{76}$

Does this tell us anything about how doctors saw their own profession? There has been considerable discussion of the status of professional doctors during the late imperial period. As a result of this there seems to be some agreement that from at least the Song dynasty medicine was a respectable occupation for a Confucian scholar since it was associated with the virtue of benevolence. This is undoubtedly true of the study of medicine and almost certainly also of publishing medical texts, but like Chang Che-chia I wonder whether it was really true of those who actually earned a living as doctors. ${ }^{77}$ For within the Confucian framework linking the practice of medicine to personal profit was inherently problematic. Families inviting a doctor tried to deal with this contradiction by treating the doctor as an honoured friend. Thus Liu often went in person to fetch the doctor and was once asked by his granddaughter's husband's father to go to a neighbouring village to invite a doctor called Bai 白 who was a specialist in children’s diseases to come to the family. ${ }^{78}$ Liu Dapeng was highly educated and well respected; to send him to fetch the doctor was a compliment that attempted to transform the doctor into a friend. But the tension between the idea of healing as an expression of personal relationships and the doctor's need to earn a living meant that such methods did not 
always work. Doctors too must have been aware of the problem. Doctors and medicine shops sacrificed to the medicine deities at Jinci, the local town and major temple complex, as a group which implies that they saw themselves as a professional group, but also that they acknowledged that their work was part of the interaction between the divine and human worlds. ${ }^{79}$ Indeed professional doctors were problematic precisely because medical treatment was linked to the rebuilding of a disrupted moral order that had angered the divine world.

\section{Divine aid}

An alternative to employing a doctor was to ask directly for divine aid in choosing medication. Most villages had a shrine to the Medicine Kings, who Liu explained as being great doctors of antiquity and authors of medical texts. Women also worshipped the Smallpox Goddess, Guanyin Who Sends Sons and various other fertility goddesses. There was a temple to Guanyin Who Sends Sons at Jinci and it was customary to take one of the small statues of boys from the shelf behind the deity home for a year while praying for a son. ${ }^{80}$ Missionaries tell us of papers pasted up near a holy tree telling of answers to prayers for healing. ${ }^{81}$ Like many other people Liu Dapeng was convinced of the efficaciousness of prayer offered to the Taoist immortal Lu Dongbin 呂洞賓 who had a temple at Jinci and a busy three-day annual festival. ${ }^{82}$ In his old age Liu records going up to this temple and making an offering to the god to beg him to heal a minor skin complaint. He also burnt a prayer beginning, 
On the 15th of the 8th month of the 29th year of the Republic of China, your grateful servant Liu Dapeng, an old man from Chiqiao village, worships in front of the holy tablet of the Great Immortal saying: Only our Great Immortal approaches this place and heals illnesses for the people... ${ }^{83}$

In answer to a prayer of this sort he would have received one of the prescriptions kept in the temple and drawn by lot. These had been placed there in the 1860s, when a local man, who had experienced an amazing cure had paid to have them copied from the prescriptions of the Lu Dongbin temple in Taiyuan city. Another set of prescriptions was pasted on the outside wall of the main temple of the Holy Mother. ${ }^{84}$ Prescriptions acquired by divine aid of this sort were couched in the language of classical diagnosis and treatment. When Liu Dapeng was ill with a neck pain in 1901 his parents sent him a diagnosis and prescription obtained from a friend who was a spirit medium expert at planchette writing. The diagnosis explained that the illness was a syndrome of the liver and lungs caused by a heteropathic wind that had entered the two organs and, being unable to circulate, had caused depletion of the blood. Liu knew that his parents had taken medicines from this source several times and found them effective. So he went out and bought the ingredients, which he complained were very expensive, and took eight doses, but then the local pharmacies ran out of one of the ingredients, he was still not better and he gave up. ${ }^{85}$ Ironically, it was in prescriptions procured by divine aid that Liu Dapeng came closest to the methods, language and pharmaceuticals of orthodox classical medicine. 
Thus the medical culture in which Liu Dapeng participated included, like many medical cultures, a mixture of different systems of explanation and types of treatment. The sick person could choose between them depending on his own understanding of his condition, and if one system did not seem to be working he was likely to try another. The overarching order that linked these systems was not in fact medical but moral. The different explanations and treatments were linked together by the affection shown by family, friends and neighbours when they advised, cared for and treated the sick person. With this care and affection they acted out the proper personal relations that lay at the base of society. In so doing they not only provided physical remedies, but also worked to restore the moral order and avert Heaven's anger.

\section{The introduction of Western bio-medicine}

But what does all this say of Western medicine? Bio-medicine has not entered our picture of local medical culture so far, but surely by 1940 it had a presence? Indeed Western medicine had first reached central Shanxi some sixty years earlier when a British medical missionary, Harold Schofield, opened a clinic in Taiyuan city. Even though Schofield was a foreigner and the medicine he used was unfamiliar, people were willing to attend the clinic and to pay for the treatment. He noticed that men with hernias began to come as soon as it became known that the trusses supplied by his clinic were better than the locally made ones. In the clinic's second year Schofield treated more than three thousand patients. Most came with chronic conditions rather than fevers and epidemic diseases, but allowing for this people appear to have tried the foreign doctor for a fairly standard range of local complaints: anaemia (particularly common among women), 
dyspepsia, bronchitis, neuralgia, skin complaints and eye diseases. ${ }^{86}$ Schofield died in 1883 and his clinic closed, however Liu Dapeng must have come into contact with Western medicine not long after this as one of the next missionary clinics to open in central Shanxi happened to be in the village in Taigu county where his father had his furniture store. In 1885 shortly after the clinic opened it was attracting four or five patients per day mainly asking to have their teeth extracted or abscesses lanced, though the missionaries also operated on cataracts, a gangrenous foot, a tumour, and a patient whose nostrils had been blocked as a result of smallpox. Three years later more patients were coming and for a much wider range of complaints: eye problems, skin diseases, indigestion, paralysis, fits, rheumatism, syphilis and many more. Moreover the patients were from quite a wide social range: wealthy bankers came and the magistrate sent his daughter, but there were also servants and beggars. ${ }^{87}$ In 1888,800 patients were treated in three months. Such large numbers of people flowing through a relatively small village can scarcely have gone unnoticed. The clinic closed before Liu Dapeng began his diary in 1892, but he must surely have heard stories about it.

Gradually the medical missionaries expanded their operations and opened several more clinics and even hospitals. In 1892 the Schofield Memorial Hospital was established in Taiyuan, in 1889 an American mission hospital in Fenyang 汾陽 county to the south, and in 1902 a Catholic hospital also in Taiyuan city. None of these institutions was particularly large relative to the size of the local population: in the early 1900s the Schofield Memorial Hospital had 20 beds and St Joseph’s Catholic Hospital had 15 beds. At their greatest extent the province's eleven missionary hospitals had a total of 1,025 beds. ${ }^{88}$ Missionary doctors treated a mixture of common complaints such as skin, lung 
and digestive problems, eye diseases where they were known to perform spectacular cures with their cataract operations, and insoluble problems such as nervous complaints. Their continuing popularity is suggested by the success of a scam conducted as late as 1916 by some men who arrived at a local inn and distributed handbills saying that they had been sent out by a Christian Medical Hall. Patients thronged the inn yard and miraculous cures were reported. The men began to be invited to people's homes and collected advance payments for medicines which they claimed they were sending for from headquarters. They then disappeared with the money. ${ }^{89}$ Missionary clinics were the first organisations to make Western bio-medicine available in the villages and there is no evidence that people were unwilling to make use of them. The clinics claimed spectacular cures and certainly they attracted people with eye complaints from great distances. But, as Liu Dapeng's failure to mention them suggests, they were only ever a rather small part of the medical scene, a fact that was no doubt exacerbated by their efforts to procure religious conversion at the same time as healing.

Missionary clinics were important in introducing Western medicine to Shanxi, but they were always limited in scale. Somewhat more important was the role played by the Republican provincial government under Yan Xishan 閻錫山 (1883-1960). For most of the nineteenth century the Qing state had been committed to promoting the same moral order that men like Liu Dapeng expressed when they sought treatment for their illnesses. Confucian values were taught through the education system and confirmed through the examinations for public office, and local officials repented their sins and joined villagers in the search for divine aid during epidemics and other disasters. ${ }^{90}$ The attitudes and values of the members of the Republican government who came to power in 1911 were 
quite different. Yan Xishan, who ruled Shanxi from 1911 to 1937, saw medicine firstly as an arena for modernisation and secondly as a trade issue. He himself had studied in Japan in the 1900s and had been impressed by bio-medical treatment there and especially the use of the latest technology, X-ray machines. However, he was also concerned with the province's balance of payments, and saw that much of the medicine used in Shanxi was imported from other provinces. He therefore supported the development of Shanxi's own medicines with the aim of import substitution. ${ }^{91}$ These two attitudes were in constant tension, since modernisation implied the use of Western medicine and imports, whereas import substitution involved the development of traditional products. The result was the establishment of a large and well funded Research Association for the Improvement of Chinese Medicine, which would create a medicine that was at once Chinese and modern. ${ }^{92}$ This association, with its teaching and publications, laid some of the foundations for the national adoption of a modernised form of traditional medicine in the 1950s.

But state-sponsored modern medicine was also part of a more general process of increasing state penetration and the transfer of resources from rural areas to the building of new urban institutions. This process began with the late Qing reforms of the 1900s and its medical aspects emphasised germ theory and the enforcement of hygiene. Thus the newly formed police service played a key role and in 1909 a Police Hygiene Department was founded with offices for public health and for medicine. The next year the department established its own hospital with two doctors, a pharmacist and an isolation ward for infectious diseases. ${ }^{93}$ The police operation gradually expanded after the revolution but it remained very small and hardly impinged on people's consciousness 
at all until bubonic plague struck northern Shanxi in 1918. The outbreak lasted more than two months and 2,664 people were said to have died. The provincial government's response was strictly in line with germ theory. Indeed Yan Xishan issued a set of instructions to officials about the plague which informed them that the disease was spread by tiny germs which were breathed into the lungs and thus caused the illness. Moreover the disease was incurable so physical isolation was the only means by which it could be controlled. In this document and in telegrams from the provincial government local officials were ordered to impose strict isolation on all plague cases: family members should be kept away from the sick and dead, people must be ordered not to help infected neighbours and, if necessary, whole villages should be isolated. Police should guard the houses of the sick if necessary to achieve this ${ }^{94}$ Such methods were diametrically opposed to the popular medical culture with its emphasis on restoring the moral order through the expression of personal relationships, and it was not surprising that there was resistance at every level. Magistrates printed and issued prescriptions for remedies, village elders concealed cases, and ordinary people clothed the dead for burial and rioted when they heard that a pathological examination had been held. ${ }^{95}$ Thus the new state endorsement of germ theory and the emphasis on policing that this implied usually had little more impact than the missionary clinics, but when it such ideas were actually enforced on a large scale there was bound to be resistance.

However, with the exception of this dramatic case, state-sponsored modern medicine was heavily concentrated in Taiyuan, the provincial capital, since almost all the hospitals and teaching establishments were located there. As early as 1906 a modernstyle school teaching medicine had been established in Taiyuan. This taught the classical 
tradition of Chinese medicine and was closed down in 1912 when the new Republican government issued a strictly bio-medical syllabus for medical schools. Later the Research Association for the Improvement of Chinese Medicine 山西中醫改進研究會 established its own school and teaching hospital bringing in teachers trained in Japan. At first this taught an eclectic mixture of Chinese and Western traditions in line with the association's aims, but later it switched to an entirely bio-medical syllabus. ${ }^{96}$ By 1949 three of the total of seven government-run hospitals in the province were in Taiyuan city. There were also several small private hospitals run by pharmacies, but these too seem to have been mainly in the provincial capital. ${ }^{97}$

Outside Taiyuan there were grand plans for clinics and hygiene offices at each administrative level down to the village. The province's ten year development plan published in 1932 envisaged every village providing a room for a hygiene worker in five years time. ${ }^{98}$ The county where Liu Dapeng lived issued its own ten year plan announcing its intention to establish a county hospital providing Chinese and Western medicine, and then district and village clinics. ${ }^{99}$ However there is no indication that any of these plans were ever implemented, and old people I interviewed in the 1990s told me that there were no state-sponsored medical institutions in the county until the 1950s. ${ }^{100}$ With the physical infrastructure of modern medicine concentrated in Taiyuan city, there were attempts by the state to extend the influence of modern medical ideas by other means. Thus the provincial government moved to professionalise medical treatment. The government repeatedly tried to get doctors who had not received a formal modern training to take an examination and pay a registration fee in order to receive a license to practise. However, a newspaper announcement in 1935 saying that four doctors had 
passed the exam suggests that not many doctors bothered to participate. ${ }^{101}$ Yan Xishan also tried to spread modern medical ideas in his pamphlets What People Need to Know 人 民須知 and What Families Need to Know 家庭須知. Both of these include sections on hygiene which mix ideas from contemporary Western medicine with traditional health advice. Thus he urges people to keep rooms clean and well-ventilated since sunlight can prevent illness. Streets too should be swept and rubbish should not be allowed to pile up since smelling the noxious vapours it produces may make you ill. Infectious diseases are caused by small creatures that enter the body by breathing, eating or through cuts in the skin. The reader is advised not to eat too many things that are hard to digest, not to drink unboiled water, not to eat to satiety, to wash cooking pots frequently, and to ensure that children are vaccinated. ${ }^{102}$ How many people actually attended to these pamphlets is however unknown.

This brief institutional history suggests that some of the ideas and practices of contemporary bio-medicine were available in central Shanxi. But to what extent were they actually absorbed into the medical culture of the village? Florence Bretelle-Establet has argued that in parts of southwest China Western medicine was extremely widely used. Indeed she suggests that in 192150 percent of the local population in the area she studied made use of the Western clinics. ${ }^{103}$ But this was in an area where sizeable medical institutions had been established and were paid for by the French government. The situation was quite different in Shanxi, where the institutions of bio-medicine whether missionary or government-run were scattered and even those in the provincial capital were small. However, there were two features of Western medicine that did reach Chiqiao village: vaccination and the use of cows milk. In addition the advertisements Liu 
Dapeng would have come across when he read the local newspaper would have made him aware of some of the Western institutions and medication available in the provincial capital.

Vaccination against smallpox had first reached the area in the 1860s when a doctor in Yuci 榆次 county read a book by a Cantonese author on the new method and wrote a manual promoting it. ${ }^{104}$ Vaccination involved the insertion of vaccine (derived ultimately from the cowpox virus) into a cut in the arm of the child. Previously immunisation had been achieved by variolation which involved blowing a powder of dried smallpox pustules into the nose. Variolation gave the child a mild attack of smallpox, whereas vaccination had the advantage that the child did not become sick at all. The new method was perceived as something of foreign origin. A late Qing vaccination manual that circulated in the area makes it quite clear that the technique had been invented by the Englishman Jenner and that it had reached China through Macao. ${ }^{105}$ Moreover Liu Dapeng's grandson remembers learning about Jenner at primary school in the 1930s. ${ }^{106}$ But although people were aware of the foreign origins of vaccination they also made sense of it in traditional terms. When a government bureau was set up in 1874 to provide vaccination it operated only in the spring and autumn, the traditional times for variolation. ${ }^{107}$ Moreover the manual for doctors gives diagrams showing how the vaccine should be introduced at two major acupuncture points in the arms. In this way vaccination was rapidly adopted in the area. According to Liu Dapeng's friend Liu Wenbing, in the 1870s ninety percent of children were vaccinated in Xugou county. ${ }^{108}$ Public vaccination was ordered for the first time by the provincial governor in $1882 .{ }^{109}$ Liu recorded trips to have three of his children and grandchildren vaccinated in 1914 and 
another grandson still bares the mark where his arm was scratched and the vaccine rubbed in. This man whose mother died shortly after his birth in 1926, remembered that his wetnurse had a pockmarked face but that she was one of the few remaining in the village. ${ }^{110}$ People did not necessarily trust government vaccinators: there was a rumour in the 1880s that they had run out of lymph and were using condensed milk. ${ }^{111}$ But vaccination was also provided by individual doctors or lay specialists and as such it was successfully absorbed into the local medical culture.

The idea that vaccinators were using milk instead of vaccine makes sense because milk was the other really widespread Western health product. As Yeh Wen-hsin has pointed out, milk was promoted in a variety of newspapers and magazines at this time as both health giving and a symbol of the modern family. ${ }^{112}$ In 1926 Liu’s family invited the doctor but also bought milk powder to feed a grandchild whose mother had no breast milk. ${ }^{113}$ A few years earlier Liu’s wealthy acquaintance Chang Zanchun repeatedly injected his poor wife, to whom he was devoted and who was ill after giving birth to a child, with lactose. ${ }^{114}$ The injection and the use of milk products show the influence of Western medicine, but the treatment took place within a context of personal relationships and was controlled by family members. Chang Zanchun's wife died as did Liu's little grandson and more famously Sun Yatsen after his operation.

Many other foreign health products were also available in shops in the provincial capital. As early as 1904 missionaries reported that codliver oil was sold in Taiyuan and that it was possible to persuade patients to buy and take it. ${ }^{115}$ The first specialist biomedical pharmacy, the Sino-Western Pharmacy 中西藥房 opened in the city in 1913 and was followed by several more. ${ }^{116}$ In the 1920s and 30s several of these pharmacies 
advertised in the local newspapers, which were available in the village and which Liu Dapeng often read. The Jin’an Pharmacy 晉安藥房 boasted of selling medicine from Europe, America, Beijing 北京, Shanghai 上海, Tianjin 天津 and Hankou 漢 $\square$ and that it employed a graduate of a Western-style medical college as well as a Chinese-style doctor. Another advertisement, for the Five Continents Pharmacy 五洲大藥房, emphasises that the Western-style doctors in the pharmacy will give injections, which again marks the experience of treatment as modern and different. ${ }^{117}$ Some Western treatments, such as Pinkettes, a version of a patent medicine known as Dr. Williams Pink Pills for Pale People, and Doaks skin medicine were also advertised in the local press. A medicine for curing pockmarks which was sold by a pharmacy that had branches in many Shanxi county towns boasted that it has been discovered by an American skinspecialist. ${ }^{118}$ Others, particularly treatments for headaches, were also sold in local pharmacies. ${ }^{119}$ Such advertisements might spread interpretations of illness as well as the pharmaceuticals they offered for sale. Thus an advertisement for a remedy for skin

diseases explains that it can cure ringworm because it kills the worms and germs. ${ }^{120}$ Thus bio-medical treatments and pharmaceuticals were available in early twentiethcentury Shanxi, even though they did not play a particularly large role in the local medical culture.

\section{Conclusion}

Western medicine existed in rural Shanxi but it functioned within the networks of family and community that structured the experience of other forms of medicine. Villagers' ideas of community in the context of medical treatment were quite different from those of 
the state. Villagers saw ever widening circles of care and concern spreading out from the individual through family, neighbours and friends. The state on the other hand saw a descending hierarchy of administrative units controlled from above. Thus the building of medical institutions centralised in the provincial capital divorced care from the network of the community and ideas of the Confucian moral order. To some extent this process was the result of changes in the intellectual framework used to interpret sickness and health, and in particular the move towards science and germ theory. However, in the village there was little sense of bio-medicine as a theoretical system that could be contrasted with a single Chinese medical system. Indeed the local medical culture included a variety of different approaches ranging from the popular understanding of illness as a poison that needed to be expelled from the body, through more sophisticated textual approaches which people knew existed even if they did not understand them, to prayers to a variety of local deities. Moreover people knew that fashions in medical treatment changed through time. Thus Liu Dapeng's enthusiasm for violent purges was old-fashioned even at the beginning of the twentieth-century. What united these different approaches were the human relationships through which they were applied and the moral order though which they were judged. When new bio-medical ideas came they were judged in terms of the same framework. Thus when foreign missionary doctors helped the government implement its unpopular quarantining policies to prevent plague, people complained that the missionaries were only doing this because they hoped to profit from it. $^{121}$ The Five Continents Pharmacy, which sold Western medicine in Taiyuan, actually ran an advertisement to repair its reputation when someone claimed that it was selling medicines to make a profit rather than to save lives. ${ }^{122}$ When the Republican state 
promoted bio-medical ideas it was as part of a process of abandoning the Qing state's involvement with the promotion of the Confucian moral order. The new medical system was cut off from the process through which the curing of illness created and reinforced the moral order and thus social structures. Instead the state promoted medical institutions and professionalisation in the context of an increasingly visible urban consumer culture. The risk was that modern medicine would be perceived as entwined with personal profit and thus running directly counter to the traditional moral order.

Bibliography

ABCFM. Papers of the American Board of Commissioners for Foreign Missions. Houghton Library. Harvard University.

Andrews, Bridie J. "Tuberculosis and the Assimilation of Germ Theory in China, 18951937” Journal of the History of Medicine and Allied Sciences 52 (1997).

Benedict, Carol. Bubonic Plague in Nineteenth-Century China. Stanford: Stanford University Press, 1996.

Berg, Daria. "Perceptions of Lay Healers in Late Imperial China” Durham East Asian Papers 15 (2000).

Bretelle-Establet, Florence. "Resistance and Receptivity: French Colonial Medicine in Southwest China, 1898-1930” Modern China 25.1 (1999) Che-chia, Chang. The Therapeutic Tug of War - The Imperial Physician-patient Relationship in the Era of Empress Dowager Cixi (1874-1908). Ph.D. University of Pennsylvania, 1998.

Chia-Feng, Chang. Aspects of Smallpox in Chinese History. Ph.D. School of Oriental and African Studies, University of London, 1996. 
Chang Zanchun 常贊春, Changshi jiacheng 常氏家乘 [Family records of the Chang surname] c. 1920.

Cullen, Christopher. "Patients and Healers in Late Imperial China: Evidence from the Jinpingmei” History of Science 31.2 (1993).

Feng Hefa 馮和法. Zhongguo nongcun jingji ziliao 中國農村經濟資料 [Economic materials on Chinese villages]. Shanghai: Liming shuju, 1933.

Guo Yuanzhou 郭怨舟. “Qingmo minchu Taiyuan zhiming xuezhe: Hu Haifeng” 清末民 初太原知名學者一胡海峰 [Hu Haifeng: A well known scholar in the late Qing and early Republic] Taiyuan wenshi ziliao 太原文史資料 8 (1987).

Hanson, Marta. "Merchants of Medicine: Huizhou Mercantile Consciousness, Morality, and Medical Patronage in Seventeenth-century China” in Hashimoto Keizo, Catherine Jami and Lowell Skar ed.s., East Asian Science: Tradition and Beyond. Osaka: Kansai University Press, 1995.

Harrison, Henrietta. "Newspapers and Nationalism in Rural China” Past and Present 166 (2000). . The Man Awakened from Dreams: One Man's Life in a North China Village 18571942. Stanford: Stanford University Press, 2005.

Hymes, Robert P. "Not quite gentlemen? Doctors in Sung and Yuan” Chinese Science 8 (1987).

Jinyang ribao 晉陽日報 [Jinyang Daily].

Jinzhong diquzhi 晉中地區志 [Central Shanxi district gazetteer]. Taiyuan: Shanxi renmin chubanshe, 1993. 
Kleinman, Arthur. Patients and Healers in the Context of Culture: An Exploration of the Borderland between Anthropology, Medicine, and Psychiatry. Berkeley: University of California Press, 1980.

Leung, Angela Ki Che. "Medical instruction and popularisation in Ming-Qing China” Late Imperial China 24.1 (2003).

Li Shiyu 李時雨. “Hu Ying” 胡瀛 [Hu Ying] Taiyuan wenshi ziliao 8 (1987)

Liu Dapeng 劉大鵬. Jinci zhi 晉祠志 [Jinci Gazetteer] (ed. Mu Xiang and Lu Wenxing).

Taiyuan: Shanxi renmin chubanshe, 1986. . Tuixiangzhai riji 退想齋日記 [Diary from the chamber to which one retires to ponder]. MS. Shanxi Provincial Library. . Tuixiangzhai riji 退想齋日記 [Diary from the chamber to which one retires to

ponder] (ed. Qiao Zhiqiang 喬志強). Taiyuan: Shanxi renmin chubanshe, 1990.

Liu Wenbing 劉文炳. Xugou xianzhi 徐溝縣志 [Xugou county gazetteer]. Taiyuan:

Shanxi renmin chubanshe, 1992.

Liu Zuoqing 劉佐卿 (Liu Dapeng’s grandson), interviews Taiyuan.

North China Herald.

Ma Boying 馬伯英. Zhongguo yixue wenhuashi 中國醫學文化史 [A cultural history of Chinese medicine]. Shanghai: Shanghai renmin chubanshe, 1994.

Porter, Dorothy and Roy Porter, Patient's Progress: Doctors and Doctoring in Eighteenth-century England. Cambridge: Polity Press, 1989.

Porter, Roy ed. Patients and Practitioners: Lay Perceptions of Medicine in Pre-industrial Society. Cambridge: Cambridge University Press, 1985. 
Schofield, A.T. ed., Memorials of R. Harold A. Schofield M.A., M.B. (OXON) (Late of the China Inland Mission), First Medical Missionary to Shan-si, China. London: Hodder and Stoughton, 1885.

Schofield, Harold. Second Annual Report of the Medical Mission in T'ai-yüen-fu, Shansi, North China, In Connection with the China Inland Mission. Shanghai: American Presbyterian Mission Press, 1883.

Shanxi ribao 山西日報 [Shanxi daily news].

Shanxi sheng shizhi yanjiuyuan 山西省史志研究院 ed., Shanxi tongzhi: Weisheng yiyao zhi. Weisheng pian 山西通志: 衛生醫藥志.衛生篇 [Shanxi gazetteer: Hygiene and Medicine Gazetteer. Hygiene section]. Beijing: Zhonghua shuju, 1997. Shanxi sheng zhengzhi ji jingji shinian jianshe jihua'an 山溪省政治及經濟十年建設計 畫案 [Ten year construction plan for Shanxi province government and economy]. 1932. Taiyuan ribao 太原日報 [Taiyuan Daily News].

Taiyuan shi nanjiaoqu zhi 太原市南郊區志 [Taiyuan city southern suburban district gazetteer]. Beijing: Sanlian shudian, 1994.

Taiyuan xian xianzheng shi nian jianshe jihuaan 太原縣縣政十年建設計畫案 [Record of the ten year construction plan for Taiyuan county county administration]. c. 1934. Wang Qinglian 王清蓮, Wang Hansan 王漢三, "Wenshui xian lao xiangyi - Xue xiansheng" 文水縣老鄉醫-學先生 [Mr Xue, an old country doctor of Wenshui county] Shanxi wenshi ziliao 山西文史資料 29 (1983).

Watson, Percy Theodore, MS Notebook on Pneumonic and Bubonic Plague. Yale Divinity School. China Records Project. Miscellaneous Personal Papers. 8.208. 
Wu Shouming 武壽銘. Taigu xian Guanjiabu cun diaocha baogao 太谷縣貫家堡村調查 報告 [Report on an investigation into Guanjiabu village, Taigu county]. MS, 1935. Collection of Professor Xing Long 行龍, Shanxi University. Xiao Zhushan 蕭竹山, “Cong Qi Biaojia riji kan wan Ming Jiangnan shiren de richang shenghuo shi - yi yiliao huodong weili” 從 祁彪佳日記 看晚明江南士人的日常生活 史 一醫療活動為例 [Looking at the history of the everyday life of Jiangnan literati in the late Ming from the Diary of Qi Biaojia - case study of medical activities]. Paper given at a conference on Ming Qing de shehui yu shenghuo 明清的社會與生活, Zhongyang yanjiuyuan lishi yuyan yanjiusuo, Jinan guoji daxue lishixi 中央研究院歷史語言研究所 暨南國際大學歷史系, Taibei, 19 December 2001.

Yan Xishan 閻錫山. Zhi Jin zhengwu quanshu chubian 治晉政務全書初編 [Complete works on the government of Shanxi, first collection]. In Yan Bochuan xiansheng quanji 閻伯川先生全集 [Complete works of Mr Yan Xishan] [c. 1928].

_. Yan dujun zhengshu 閻督軍政書 [The political writings of Military Governor Yan]. Shanghai shangyou she, 1920. Yang Mingwen 楊明文. “Shanxi zuizaode yisuo yiyuan” 山西最早的一所醫院 [Shanxi’s earliest hospital] Shanxi wenshi ziliao 山西文史資料 84. Yeh Wen-hsin. "Shanghai Modernity: Commerce and Culture in a Republican City” China Quarterly 150 (1997). Yong Heguang 永和光. Zhongdou xinshu 中斗新書 [New book on smallpox vaccination] 1922 edition of a Qing text. MS. Author’s collection. 


\section{Zhang Zhengming 張正明. Shanxi lidai renkou tongji 山西歷代人口統計 [Shanxi}

historical population statistics]. Taiyuan: Shanxi renmin chubanshe, 1992.

Zhu Zhewen 朱哲文. “Jiefang qiande Taiyuan yiyao weisheng shiye” 解放前的太原醫藥

衛生事業 [Medical and hygiene work in Taiyuan before liberation] Taiyuan wenshi ziliao 太原文史資料 6 (1986).

\footnotetext{
${ }^{1}$ I would like to thank Marta Hanson and Kim Taylor for reading and commenting on earlier drafts of this paper.

${ }^{2}$ See particularly Dorothy Porter and Roy Porter, Patient’s Progress 1989, Roy Porter ed., Patients and Practitioners 1985.

${ }^{3}$ Arthur Kleinman, Patients and Healers in the Context of Culture, 1980.

${ }^{4}$ Chang Che-chia, The Therapeutic Tug of War, 1998.

${ }^{5}$ Christopher Cullen, “Patients and Healers in Late Imperial China,” 1993; Xiao Zhushan, “Cong Qi Biaojia riji kan wan Ming Jiangnan shiren de richang shenghuo shi”; Daria Berg, "Perceptions of Lay Healers in Late Imperial China”, 2000.

${ }^{6}$ Bridie J. Andrews, “Tuberculosis and the Assimilation of Germ Theory in China”, 1997.

${ }^{7}$ Liu Dapeng, Tuixiangzhai riji, (ed Qiao Zhiqiang) 1990, p. 1-5. See also Henrietta Harrison, The Man Awakened from Dreams, 2005.

${ }^{8}$ Liu Dapeng, Tuixiangzhai riji MS. Unfortunately the published version of the diary edited by Qiao Zhiqiang is heavily abridged and contains almost none of the medical material. Diary references are given here by the CE year number followed by the lunar month and day. Where references to the published text are possible I have given them in brackets after the reference to the manuscript.

${ }^{9}$ Liu Dapeng, Tuixiangzhai riji 1914/1/11, 1914/3/24-28, 1914/4/22, 1914/7/5-13, 1914/8/29.

${ }^{10}$ Zhang Zhengming, Shanxi lidai renkou tongji, 1992, p. 233.

${ }^{11}$ Feng Hefa, Zhongguo nongcun jingji ziliao, 1933, p. 737.

${ }^{12}$ North China Herald 27 August 1902, p. 419-20.
} 
${ }^{13}$ Taiyuan shi nanjiaoqu zhi, 1994, p. 781; Taiyuan xian xianzheng shi nian jianshe jihuaan, 1934, n.p.;

Shanxi ribao, 10 September 1919, p. 3.

${ }^{14}$ Taiyuan xian xianzheng shi nian jianshe jihuaan, n.p.

${ }^{15}$ Liu Wenbing, Xugou xianzhi, 1992, p. 304. For Liu Wenbing as an acquaintance see Liu Dapeng,

Tuixiangzhai riji 1901/6/11.

${ }^{16}$ North China Herald, 2 June 1917, p. 488.

${ }^{17}$ Liu Dapeng, Tuixiangzhai riji 1901/6/4.

${ }^{18}$ Wu Shouming. Taigu xian Guanjiabu cun diaocha baogao, 1935, p. 73.

${ }^{19}$ Harold Schofield, Second Annual Report of the Medical Mission in T'ai-yüen-fu, 1883, p. 29.

${ }^{20}$ Harold Schofield, p. 1-9.

${ }^{21}$ ABCFM. Shansi Mission. Minutes of the Sixth Annual Meeting of the Shanse Mission of the American Board, 1888.

${ }^{22}$ Liu Dapeng, Tuixiangzhai riji 1926/11/1-1926/12/22.

${ }^{23}$ Liu Dapeng, Tuixiangzhai riji 1925/12/26.

${ }^{24}$ Liu Dapeng, Tuixiangzhai riji 1902/12/8 (Qiao ed. p. 118), for his income see 1896/2/4 (Qiao ed. p. 55).

${ }^{25}$ Harold Schofield, p. 17; ABCFM. Shansi Mission. Taiku Medical Work, 1908-9.

${ }^{26}$ Liu Dapeng, Tuixiangzhai riji 1925/intercalary 4/8.

${ }^{27}$ Liu Dapeng, Tuixiangzhai riji 1908/6/3.

${ }^{28}$ Liu Dapeng, Tuixiangzhai riji 1925/1/19.

${ }^{29}$ Liu Dapeng, Tuixiangzhai riji 1926/7/26. For Cao Dinghai’s occupation interviews Chiqiao 2 August 2001.

${ }^{30}$ Liu Dapeng, Tuixiangzhai riji 1914/1/11.

${ }^{31}$ Liu Dapeng, Tuixiangzhai riji 1926/11/21.

${ }^{32}$ Liu Dapeng, Tuixiangzhai riji 1901/6/4.

${ }^{33}$ Liu Dapeng, Tuixiangzhai riji 1926/12/6, 1940/5/20 (Qiao ed. p. 349, 557).

${ }^{34}$ Liu Dapeng, Tuixiangzhai riji 1925/4/29-5/28.

${ }^{35}$ Liu Dapeng, Tuixiangzhai riji 1903/6/1 (Qiao ed. 125), 1908/6/2, 1925/ intercalary 4/2, 1926/6/14; Liu Zuoqing (Liu Dapeng’s grandson, born 1926) interview, 6 August 1999. 
${ }^{36}$ Liu Wenbing, p. 304-5.

${ }^{37}$ Harold Schofield, p. 11.

${ }^{38}$ Eg. Liu Dapeng, Tuixiangzhai riji 1908/6/1. For the widespread medical use of opiates as pain killers see ABCFM Shansi. Minutes of the Sixth Annual Meeting of the Shanse Mission of the American Board, 1888. However, Liu Dapeng does not seem to have used opium against pain.

${ }^{39}$ Liu Dapeng, Tuixiangzhai riji 1901/1/28.

${ }^{40}$ Liu Dapeng, Tuixiangzhai riji 1901/2/10, 1925/intercalary 4/4; Liu Zuoqing, 6 September 1999. See also ABCFM Shansi. Minutes of the Sixth Annual Meeting of the Shanse Mission of the American Board, 1888.

${ }^{41}$ Liu Dapeng, Tuixiangzhai riji 1925/intercalary 4/22.

${ }^{42}$ Liu Dapeng, Tuixiangzhai riji 1901/2/6, 1925/intercalary 4/10-12; Liu Zuoqing, interview 6 September 1999.

${ }^{43}$ Liu Dapeng, Tuixiangzhai riji 1901/4/27, 1925/intercalary 4/11, 1926/11/27.

${ }^{44}$ Liu Dapeng, Tuixiangzhai riji reverse of 1926/12/22.

${ }^{45}$ Liu Dapeng, Tuixiangzhai riji reverse of 1926/12/21.

${ }^{46}$ For sunning the legs see Liu Dapeng, Tuixiangzhai riji 1901/6/15.

${ }^{47}$ Liu Dapeng, Tuixiangzhai riji 1925/intercalary 4/4-11.

${ }^{48}$ Liu Dapeng, Tuixiangzhai riji 1926/8/21.

${ }^{49}$ Chang Zanchun, Changshi jiacheng, 1920, p. 15-17.

${ }^{50}$ North China Herald, 10 May 1924 p 208. This reports that the incident was discussed in the local newspapers. Unfortunately the Jinyang Daily (Jinyang ribao) for 1924 does not survive.

${ }^{51}$ Liu Dapeng, Tuixiangzhai riji 1901/2/21.

${ }^{52}$ Liu Dapeng, Tuixiangzhai riji 1901/2/10, 1901/4/24.

${ }^{53}$ Liu Dapeng, Tuixiangzhai riji 1926/4/26.

${ }^{54}$ Liu Dapeng, Tuixiangzhai riji 1903/6/1 (Qiao ed. p. 125), 1926/8/1; Liu Zuoqing interviews 6 August 1999, 7 August 2002.

${ }^{55}$ Liu Dapeng, Tuixiangzhai riji 1926/11/8.

${ }^{56}$ ABCFM. Shansi Mission. T’ai Ku Station of Shansi Mission. Medical Work 1904-5.

${ }^{57}$ Liu Dapeng, Tuixiangzhai riji 1901/1/23, 1926/11/18. 
${ }^{58}$ Liu Dapeng, Tuixiangzhai riji 1901/1/26-28. C.f. Cullen.

${ }^{59}$ Liu Dapeng, Tuixiangzhai riji 1925/2/23, 1926/6/26.

${ }^{60}$ Liu Dapeng, Tuixiangzhai riji 1927/12/9, 24 (Qiao ed. p. 363).

${ }^{61}$ Liu Zuoqing interview 28 July 2001.

${ }^{62}$ Chang Chia-Feng, Aspects of Smallpox in Chinese History, 1996; Cullen.

${ }^{63}$ Liu Dapeng, Tuixiangzhai riji 1894/4/10 (Qiao ed. p. 33), 1897/2/10 (Qiao ed. p. 70), 1925/7/23. C.f.

Xiao Zhushan.

${ }^{64}$ Liu Dapeng, Tuixiangzhai riji 1892/7/4, 1921/1/8 (Qiao ed. p. 286), 1925/12/2, 1926/1/17, 1926/6/28.

For Hu Ying’s life see Guo Yuanzhou, “Qingmo minchu Taiyuan zhiming xuezhe: Hu Haifeng”, Li Shiyu, "Hu Ying”.

${ }^{65}$ Liu Dapeng, Tuixiangzhai riji 1901/10/26.

${ }^{66}$ Wang Qinglian, Wang Hansan, “Wenshui xian lao xiangyi” 1983. For the texts studied by these men see Angela Ki Che Leung, "Medical instruction and popularisation in Ming-Qing China,”2003.

${ }^{67}$ Shanxi sheng shizhi yanjiuyuan ed., Shanxi tongzhi: Weisheng yiyao zhi. Weisheng pian, 1997, p. 48-9, 74-9.

${ }^{68}$ Ma Boying, Zhongguo yixue wenhuashi, 1994. See also Chang Che-chia, p. 68-9.

${ }^{69}$ E.g. Liu Dapeng, Tuixiangzhai riji 1892/9/27.

${ }^{70}$ Liu Dapeng, Tuixiangzhai riji 1896/4/11 (Qiao ed. p. 57).

${ }^{71}$ Liu Dapeng, Tuixiangzhai riji 1926/11/12.

${ }^{72}$ Liu Dapeng, Tuixiangzhai riji 1926/11/20.

${ }^{73}$ Liu Dapeng, Tuixiangzhai riji 1892/9/27.

${ }^{74}$ Liu Dapeng, Tuixiangzhai riji 1901/2/18, 1905/7/14 (Qiao ed. p. 144).

${ }^{75}$ Liu Dapeng, Tuixiangzhai riji 1925/11/26.

${ }^{76}$ Taiyuan xian xianzheng shinian jianshe jihuaan, n.p.

${ }^{77}$ Robert P. Hymes, “Not quite gentlemen? Doctors in Sung and Yuan” 1987; Marta Hanson, "Merchants of Medicine”, 1995; Ma Boying; Chang Che-chia.

${ }^{78}$ Liu Dapeng, Tuixiangzhai riji 1926/2/14. C.f. Xiao Zhushan.

${ }^{79}$ Liu Dapeng, Jinci zhi, p. 183-5. 
${ }^{80}$ Liu Wenbing, p. 280; Liu Dapeng, Jinci zhi, p. 181-5; interview Chiqiao 3 August 1999.

${ }^{81}$ A.T. Schofield ed., Memorials of R. Harold A. Schofield, 1885, p. 174.

${ }^{82}$ Liu Dapeng, Jinci zhi, p. 180-1.

${ }^{83}$ Liu Dapeng, Tuixiangzhai riji 1940/8/15 (Qiao ed., p. 561).

${ }^{84}$ Liu Dapeng, Jinci zhi, p. 650-1.

${ }^{85}$ Liu Dapeng, Tuixiangzhai riji 1901/2/21, 1901/3/3.

${ }^{86}$ Harold Schofield, p. 10-11.

${ }^{87}$ ABCFM. Shansi Mission. Records of the Shanse Mission ABCFM for the year 1885-6; Minutes of the Sixth Annual Meeting of the Shanse Mission of the American Board, 1888.

${ }^{88}$ Yang Mingwen, "Shanxi zuizaode yisuo yiyuan”; Shanxi sheng shizhi yanjiuyuan ed., p. 82-9; Zhu

Zhewen, “Jiefang qiande Taiyuan yiyao weisheng shiye” 1986.

${ }^{89}$ North China Herald, 11 November 1916, p. 306-7.

${ }^{90}$ See Carol Benedict, Bubonic Plague in Nineteenth-Century China, 1996.

${ }^{91}$ Yan Bochuan, Zhi Jin zhengwu quanshu chubian, 1928, vol. 8. p. 239; Shanxi sheng zhengzhi ji jingji shinian jianshe jihua'an, 1932, gaijin weisheng jihua’an p. 5.

92 Shanxi sheng shizhi yanjiuyuan ed., p. 17.

${ }^{93}$ Shanxi sheng shizhi yanjiuyuan ed., p. 15, 31.

${ }^{94}$ Shanxi sheng shizhi yanjiuyuan ed., p. 333, 425; Yan Bochuan, vol. 8. p. 166, 169, 195.

${ }^{95}$ North China Herald 26 January 1918, p. 185, 16 February 1918, p. 375-6; Percy Theodore Watson, MS Notebook on Pneumonic and Bubonic Plague.

${ }^{96}$ Shanxi sheng shizhi yanjiuyuan ed., p. 16, 510-12.

${ }^{97}$ Shanxi sheng shizhi yanjiuyuan ed., p. 86; Zhu Zhewen.

${ }^{98}$ Shanxi sheng zhengzhi ji jingji shinian jianshe jihuaan, p. 5.

${ }^{99}$ Taiyuan xian xianzheng shinian jianshe jihuaan, n.p.

${ }^{100}$ Liu Zuoqing interview 6 September 1999.

${ }^{101}$ Shanxi sheng shizhi yanjiuyuan ed., p. 15; Taiyuan ribao 22 September 1935, p. 5.

${ }^{102}$ Yan Xishan, Yan dujun zhengshu, 1920, vol. 1. p. 16, vol. 3. p. 5-6.

${ }^{103}$ Florence Bretelle-Establet, “Resistance and Receptivity” 1999. 
${ }^{104}$ Jinzhong diquzhi, 1993, p. 663.

${ }^{105}$ Yong Heguang, Zhongdou xinshu, 1922.

${ }^{106}$ Liu Zuoqing interview 6 September 1999.

${ }^{107}$ Zhu Zhewen. C.f. Bretelle-Establet.

${ }^{108}$ Liu Wenbing, p. 304.

${ }^{109}$ Harold Schofield, p. 29.

${ }^{110}$ Liu Dapeng, 1914/4/20; Liu Zuoqing, interview 6 September 1999.

${ }^{111}$ Harold Schofield, p. 29.

112 Yeh Wen-hsin, “Shanghai Modernity” 1997.

${ }^{113}$ Liu Dapeng 1926/4/21.

${ }^{114}$ Chang Zanchun, vol. 6. p. 18b-19a.

${ }^{115}$ ABCFM. Shansi Mission. T'ai Ku Station of Shansi Mission. Medical Work 1904-5.

${ }^{116}$ Zhu Zhewen.

${ }^{117}$ Shanxi ribao, 3 September 1930, p. 8, 9 December 1930, p. 2. For Liu Dapeng’s reading see Henrietta Harrison, “Newspapers and Nationalism in Rural China”2000.

118 Jinyang ribao, 18 August 1935, p. 4, 19 August 1935, p. 3.

${ }^{119}$ Liu Zuoqing, 6 September 1999.

${ }^{120}$ Taiyuan ribao, 22 October 1935, p. 3.

${ }^{121}$ Yan Bochuan, vol. 8. p. 200.

${ }^{122}$ Shanxi ribao, 5 September 1930, p. 6. 